\title{
Erratum zu: Öffnung der Hochschulen durch wechselseitigen Wissenstransfer im Kontext wissenschaftlicher Weiterbildung
}

\author{
Jennifer Blank ${ }^{1} \cdot$ Marina Wiest $^{1} \cdot$ Sonja Sälzle $^{1} \cdot$ Christoph Bail $^{1}$
}

Online publiziert: 28. Januar 2016

(C) Die Autor(en) 2016. Dieser Artikel ist auf Springerlink.com mit Open Access verfügbar.

\section{Erratum zu: ZfW (2015) 38(3):365-379 \\ DOI 10.1007/s40955-015-0044-7}

Bei der Publikation des oben genannten Beitrags wurdeAbb. 3 fehlerhaft veröffentlicht. Die Werte zu ,akademischer Abschluss“ wurden vertauscht.

Die korrekte Abbildung finden Sie hier:

Abb. 3 Nutzen von Weiterbildung

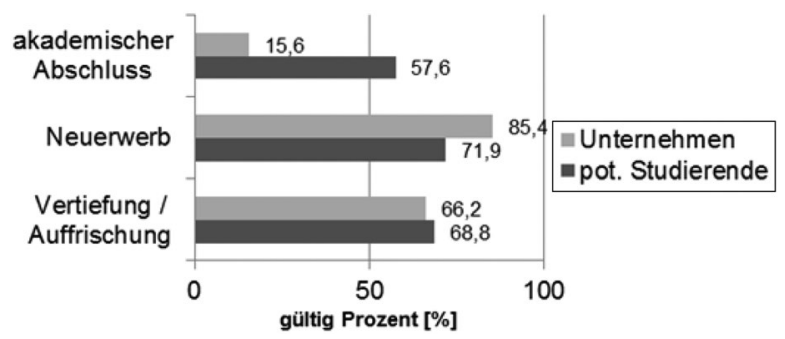

Die Online-Version des Originalartikels ist unter doi:10.1007/s40955-015-0044-7 zu finden.

Marina Wiest, M.A.

wiest@hochschule-bc.de

Dr.Jennifer Blank

blank@hochschule-bc.de

Sonja SälzleMag.

saelzle@hochschule-bc.de

Christoph Bail

bail@hochschule-bc.de

1 Zentrum für wissenschaftliche Weiterbildung, Hochschule Biberach, Karlstraße 11, 88400 Biberach, Deutschland 
Open Access Dieser Artikel wird unter der Creative Commons Namensnennung 4.0 International Lizenz (http://creativecommons.org/licenses/by/4.0/deed.de) veröffentlicht, welche die uneingeschränkte Nutzung, Verbreitung und Wiedergabe für beliebige Zwecke erlaubt, sofern Sie den/die ursprünglichen Autor(en) und die Quelle ordnungsgemäß nennen, einen Link zur Creative Commons Lizenz beifügen und angeben, ob Änderungen vorgenommen wurden. 